\title{
Clinicopathological analysis of non-gestational ovarian choriocarcinoma: Report of two cases and review of the literature
}

\author{
QIONG WANG*, CHAO GUO* , LINGFENG ZOU, YUN WANG, XIN SONG, YAQI MA and AIJUN LIU \\ Department of Pathology, Chinese People's Liberation Army General Hospital, Beijing 100853, P.R. China
}

Received December 30, 2014; Accepted January 26, 2016

DOI: $10.3892 / 01.2016 .4257$

\begin{abstract}
The aim of the present study was to analyze the clinicopathological features of two cases of non-gestational ovarian choriocarcinoma (NGCO). The histopathological, immunohistochemical and clinical features of two cases of NGCO in the left ovaries of two 13 year-old female patients were investigated and the relevant literature was reviewed. In both cases, the tumor masses exhibited cribriform, papillary and nested cellular growth patterns, and hemorrhage and necrosis were evident. In case one, the patient also exhibited a sex cord tumor with annular tubules (SCTAT) in the right ovary. To the best of our knowledge, the synchronous occurrence of these two tumor types has not been reported previously. Immunohistochemically, the tumor cells of choriocarcinoma in both cases were positive for human chorionic gonadotropin and cytokeratin, while those of SCTAT were positive for CD56 and CD99. NGCO is an extremely rare germ cell tumor of high-grade malignancy, and STCAT is even rarer. Early metastasis of NGCO is common and the disease has a poor prognosis. In the present study, one patient succumbed within 4 months of diagnosis with NGCO and the other patient was lost to follow-up after 12 months.
\end{abstract}

\section{Introduction}

Non-gestational ovarian choriocarcinoma (NGCO), which is not associated with pregnancy, is a rare germ cell tumor of high-grade malignancy that most commonly occurs in pre-pubescent females $(1,2)$. The rate of occurrence in pure primary NGOC is $<1 \%$ (3). The clinical manifestations of NGCO include vaginal bleeding, abdominal pain and

Correspondence to: Dr Aijun Liu, Department of Pathology, Chinese People's Liberation Army General Hospital, 28 Fuxing Road, Beijing 100853, P.R. China

E-mail: aliu301@126.com

*Contributed equally

Key words: ovary, germ cell tumor, sex cord stromal tumor, non-gestational choriocarcinoma, sex cord tumor with annular tubules pelvic masses, so the majority of cases are misdiagnosed and are initially treated for ovarian tumor torsion or ovarian cancer $(3,4)$. The majority of NGCO cases have been confirmed by post-surgical pathological diagnoses (4). The major treatment for NGOC is surgery combined with chemotherapy, but patients often have a poor prognosis $(3,4)$.

Sex cord tumor with annular tubules (SCTAT) is a subtype of sex cord-stromal tumor (SCST) that is also extremely rare, accounting for $2.3 \%$ of SCSTs (5). The clinical manifestations of SCTAT mainly include pelvic masses and irregular uterine bleeding, and in children SCTAT is presented as the early onset of pseudo-puberty $(6,7)$. SCTAT often occurs in women aged between 20-60 years old, and the majority of patients receive surgery combined with chemotherapy as treatment (8). In total, $\sim 21.9 \%$ cases are clinically malignant, but patients with SCTAT usually have relatively good prognosis (9). To the best of our knowledge, the co-existence of these two uncommon tumor types has not been reported in the literature to date. In the present study, two cases of NGCO are presented, one of which synchronously occurred with SCTAT of the contralateral ovary. The clinical and pathological features of these tumors, as well as patient prognosis, are presented, and the current literature is reviewed. The present study was approved by The Medical Research Ethics Committee, Chinese People's Liberation Army General Hospital (Beijing, China).

\section{Case report}

Case one. A 13 year-old female patient presented on June 5, 2012, to the Chinese People's Liberation Army General Hospital (Bejing, China) with a 20-day history of abdominal pain that had increased in severity in the previous 5 days. Menarche had not yet occurred, however, a small amount of vaginal bleeding was observed following admission. B-mode ultrasound (iU22; Phillips, Amsterdam, Netherlands) identified a $16.6 \times 10.8 \times 12.0-\mathrm{cm}$ heterogeneous solid mass in the left ovary with a clear boundary to the left of uterus. Color Doppler flow imaging (CDFI) revealed an abundant blood flow signal, as well as a small amount of free fluid in the pleural and peritoneal cavities. Positron emission tomography-computed tomography revealed soft tissue density in both lungs and multiple nodules in the greater omentum and concurrent increases in metabolism; thus, metastases were suspected. Intraoperative exploration revealed a left ovarian cystic mass, measuring $16 \times 15 \times 10 \mathrm{~cm}$, that exhibited a close association 
with the greater omentum, sigmoid colon and rectum, without clear boundaries at the uterine body. Furthermore, a 2x2-cm nodule was observed on the surface of the right fallopian tube and the right ovary measured $3.0 \times 3.0 \times 1.5 \mathrm{~cm}$ in size with a rough surface. The uterus, left ovary and fallopian tube and a portion of the right ovary were resected. Gross examination revealed a gray-red neoplastic mass measuring 12x10x8 cm in the left ovary and fallopian tube, which dark red and brown in color, and solid on the cut surface. Hemorrhage and necrosis were also evident. The tumor involved the serosa of the left wall of the uterus. The additional $15 \times 7 \times 3-\mathrm{cm}$ pelvic mass exhibited the same features as the adnexal mass. The right ovarian tumor measured $1.0 \times 0.5 \times 0.3 \mathrm{~cm}$ in size and was gray-white in color with medium hardness. Eight days postoperatively, serum $\beta$-human chorionic gonadotropin $(\beta$-hCG) levels were 2,045 U/1 (normal range, 0-5 U/1). Two cycles of chemotherapy (cisplatin, $20 \mathrm{mg}$ via intravenous drip (VD), days 1-5; bleomycin, $15 \mathrm{mg}$, VD, days 1-5; vincristine sulphate, $1 \mathrm{mg}$, VD, days 1-5) were administered. Follow-up examination performed 3 months after surgery revealed that $\beta$-hCG levels had increased to $79,102 \mu / 1$. In addition, liver, kidney and spleen metastases were identified. The patient eventually succumbed due to multiple organ failure on September 22, 2012 .

Case two. A 13 year-old female patient presented on August 6, 2012, to the Chinese People's Liberation Army General Hospital with a 1-month history of abdominal pain. A mass with a rough surface and poor mobility was identified, with light tenderness on the left side. Anal examination revealed a palpable mass in the front left of the uterus and that the corpus uteri was of normal size, however, no abnormalities were identified on the right adnexal zone. B-mode ultrasonography revealed an irregularly shaped mass in the left ovary with heterogeneous internal echo. CDFI revealed a mass with a small blood flow signal. During surgery, $200 \mathrm{ml}$ bloody ascites were observed within the left ovary by ultrasonography. In addition, a dark red nodular tumor, $12 \times 10 \times 9 \mathrm{~cm}$ in size with a rough surface, no envelope and no adhesions, was identified on the left ovary. The uterus, right fallopian tube, omental and abdominal viscera, and pelvic lymph node were normal in appearance. The left ovary and fallopian tube and tumor mass were resected. Gross examination revealed that the tumor was nodular with no envelope, and hemorrhage and necrosis were observed at the resected surface. The patient was followed up for 1 year postoperatively prior to being lost to follow-up, so the final outcome is unknown.

Microscopic examination. The resected tumors were fixed with $4 \%$ formalin (Beijing Yili Fine Chemicals Co., Ltd., Beijing, China), routinely sampled, dehydrated and embedded in paraffin (Leica Biosystems Richmond, Inc., Richmond, USA), sliced into $4-\mu \mathrm{m}$ thick sections and stained with Harris hematoxylin eosin staining and eosin staining solutions (Beijing Yili Fine Chemicals Co., Ltd.). The sections were observed under the BX53 microscope (Olympus Corporation, Tokyo, Japan).

The left ovarian tumors in cases one and two exhibited extensive hemorrhage and necrosis, and were composed of cytotrophoblasts, syncytiotrophoblasts and intermediate trophoblast cells arranged in papillary, cribriform and nest patterns. The cytotrophoblasts exhibited clear or amphophilic cytoplasms, and were oval and polygonal in shape with clear boundaries. The syncytiotrophoblasts exhibited eosinophilic or basophilic cytoplasm with cytoplasmic vacuoles and dark nuclei (Fig. 1A and B). In case one, the right ovarian tumor cells surrounding single or multiple eosinophilic hyaline bodies were arranged in a tubular formation and consisted of well-defined round or oval calcified epithelial nests. The tumor cells exhibited pale cytoplasm with nuclei palisading around the transparent bodies or cell nests (Fig. 1C and D).

Immunohistochemical staining. Resected specimens were fixed with $4 \%$ formalin (Beijing Yili Fine Chemicals Co., Ltd.), routinely sampled, embedded in paraffin (Leica Biosystems Richmond, Inc.), sliced, and stained with the hematoxylin and eosin staining solution package reagent box (Beijing Yili Fine Chemicals Co., Ltd.). Immunohistochemistry (IHC) was performed using the EnVision FLEX (DK-2600; Dako Denmark A/S, Glostrup, Denmark). The hCG (mouse monoclonal antibody; dilution, 1:150; catalog no., ZM-0134), placental alkaline phosphatase (PLAP; rabbit monoclonal antibody; dilution, 1:150, catalog no., ZA-0513), $\alpha$-fetoprotein (AFP; rabbit monoclonal antibody; dilution, 1:150, catalog no., ZM-0009), glypican-3 (GPC-3; mouse monoclonal antibody; dilution, 1:150, catalog no., ZM-0146), human placental lactogen (hPL; mouse monoclonal antibody; dilution, 1:150, catalog no., ZM-0216), CD99 (mouse monoclonal antibody; dilution, 1:150, catalog no., ZA-0577) and $\alpha$-inhibin (mouse monoclonal antibody; dilution, 1:100, catalog no., ZM-0460) antibodies were purchased from Zhongshan Jinqiao Biological Technology Co., Ltd. (Beijing, China). The CD30 (mouse monoclonal antibody; dilution, 1:100, catalog no., NCL-L-CD30-591) was purchased from Leica Biosystems Newcastle, Ltd. (Newcastle Upon Tyne, UK); cytokeratin (CK; mouse monoclonal antibody; dilution, 1:100, catalog no., M3515), CD117 (rabbit polyclonal antibody; dilution, 1:400, catalog no., A4502), CD56 (mouse monoclonal antibody; dilution, 1:100, catalog no., M7304) and smooth muscle actin (SMA; mouse monoclonal antibody; dilution, 1:100, catalog no., M0851) were purchased from Dako.

The major IHC findings of case one were as follows: i) Left ovarian tumor cells: hCG(+) (Fig. 2A), CK(+) (Fig. 2B), PLAP(-), AFP(-), CD30(-), CD117(-), GPC-3(-), hPL(-); ii) right ovarian tumor cells: CD99(+) (Fig. 2C), CD56(+) (Fig. 2D), SMA(-), CK (range + ) and $\alpha$-inhibin(-). The IHC findings of the left ovarian tumor cells of case two were as follows: hCG(+), CK(+), PLAP(-), AFP(-), CD30(-), CD117(-) and GPC-3(-).

Pathological diagnosis. In case one, non-gestational choriocarcinoma of the left ovary with a large degree of necrosis, invasion of the uterine serosa and outer muscular wall, and metastases to the omentum were diagnosed. SCTAT was also diagnosed in the right ovary. In case two, left NGCO with necrosis was diagnosed.

\section{Discussion}

Non-gestational choriocarcinoma, also known as primary choriocarcinoma, differs from gestational 

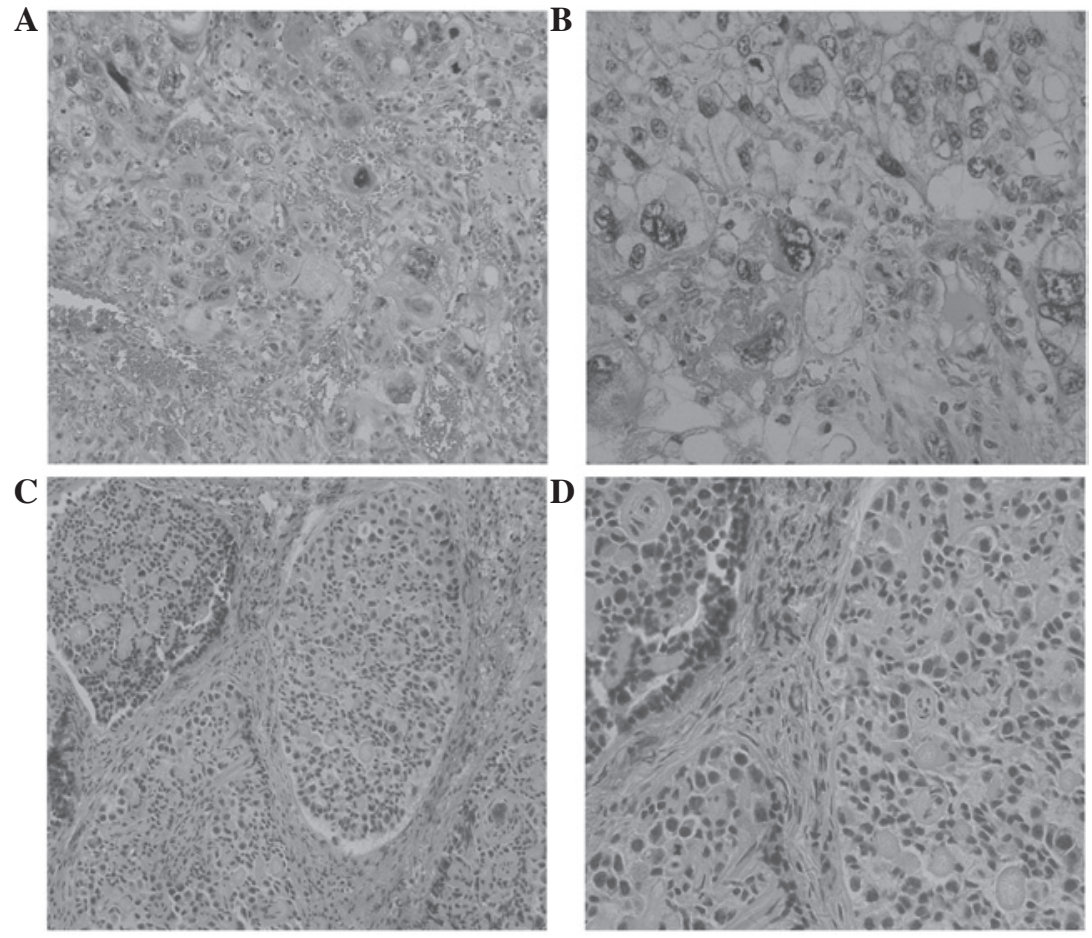

Figure 1. H\&E staining of choriocarcinoma from (A) case 1 (magnification, x200) and (B) case 2 (magnification, x400). H\&E staining of sex cord tumor with annular tubules from case 1, at (C) magnification, x200 and (D) magnification, x400. H\&E, hematoxylin and eosin.
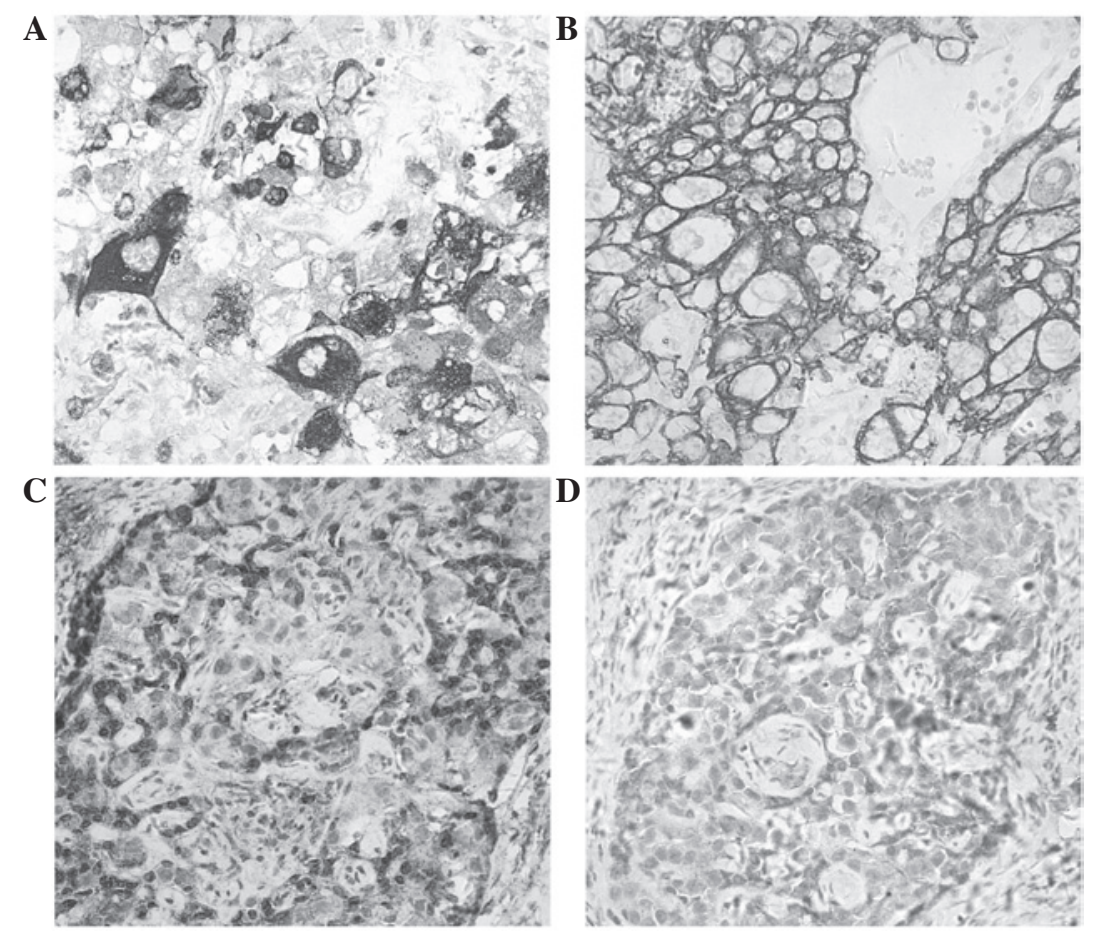

Figure 2. Immunohistochemical staining of tumors. (A) Human chorionic gonadotropin-positive and (B) cytokeratin-positive choriocarcinoma tumor cells from case 2 (magnification, x400). (C) CD99-positive and (D) CD56-positive annular tubules sex cord tumor cells from case 1 (magnification, x400). $\mathrm{CD}$, cluster of differentation.

choriocarcinoma (10). Non-gestational choriocarcinoma is not associated with pregnancy, originates in the primordial germ cells, and occurs in the reproductive organs and the extragonadal midline areas of males and females, including the pineal gland, mediastinum and retroperitoneum, as well as other organs, such as the stomach (11), lung (12) and pancreas (13). NGCO is rare, accounting for $<1 \%$ of ovarian germ cell tumors, most frequently occurring in adolescents and young females, and occasionally in postmenopausal women (14-16). Clinical manifestations include abdominal pain and pelvic 
Table I. Summary of reported cases of non-gestational ovarian choriocarcinoma.

\begin{tabular}{|c|c|c|c|c|c|c|c|c|}
\hline Author, year & $\begin{array}{l}\text { Age, } \\
\text { years }\end{array}$ & $\begin{array}{l}\text { Tumor } \\
\text { size, cm }\end{array}$ & Ovary & $\begin{array}{c}\text { Type of } \\
\text { ovarian cancer }\end{array}$ & $\begin{array}{l}\text { Metastatic } \\
\text { sites }\end{array}$ & Chemotherapy & $\begin{array}{l}\text { Follow-up } \\
\text { results }\end{array}$ & Ref. \\
\hline $\begin{array}{l}\text { Goswami et al, } \\
2001\end{array}$ & 18 & $10 \times 12$ & Left & $\begin{array}{l}\text { Contralateral } \\
\text { mature cystic } \\
\text { teratoma }\end{array}$ & - & Yes & $\begin{array}{l}\text { No recurrence } \\
\text { after } 5 \text { months }\end{array}$ & (18) \\
\hline $\begin{array}{l}\text { Gungor et al, } \\
1999\end{array}$ & 16 & $5 \times 4.3$ & Left & $\begin{array}{l}\text { Contralateral } \\
\text { dysgerminoma }\end{array}$ & $\begin{array}{l}\text { Lung and } \\
\text { pelvis }\end{array}$ & Yes & $\begin{array}{l}\text { Succumbed after } \\
6 \text { months }\end{array}$ & (19) \\
\hline Case one & 13 & $16 \times 15 \times 10$ & Left & $\begin{array}{l}\text { Contralateral sex } \\
\text { cord tumor with } \\
\text { annular tubules }\end{array}$ & $\begin{array}{l}\text { Lung and } \\
\text { pelvis }\end{array}$ & Yes & $\begin{array}{l}\text { Succumbed after } \\
3 \text { months }\end{array}$ & - \\
\hline Case two & 13 & $12 \times 10 \times 9$ & Left & $\begin{array}{l}\text { Without } \\
\text { accompanying } \\
\text { tumor }\end{array}$ & - & Yes & $\begin{array}{l}\text { Follow-up } \\
\text { discontinued } \\
\text { after } 1 \text { year }\end{array}$ & - \\
\hline
\end{tabular}

masses, tumoral secretion of hCG and, in certain cases, precocious puberty and endocrine abnormalities. The present study reported two cases in which a 13 year-old female was admitted to hospital with abdominal pain with no evident endocrine abnormalities (with the exception of a small amount of vaginal bleeding following admission in case one).

SCTAT is derived from immature cord cells that may differentiate into granular layer cells with Sertoli cell potential. SCTAT is classified as a mixed sex cord stromal tumor according to the 2014 World Health Organization classification (17).

Ovarian SCTAT, which is typically identified in young females, is relatively rare and may be divided into two subtypes: One subtype is associated with familial Peutz Jeghers syndrome (PJS; 36\%) or cervical malignant adenoma (14\%) (7), and the other subtype occurs in the absence of PJS or cervical malignant adenoma. The most common clinical manifestation of ovarian SCTAT is an abdominal mass and $40 \%$ of patients exhibit pseudo-precocious puberty or abnormal estrogen levels. In the present study, the small SCTAT tumor $(1 \times 0.5 \times 0.3 \mathrm{~cm})$ in the right ovary in case one was identified during intraoperative exploration of the left ovarian choriocarcinoma. The vaginal bleeding observed after admission may have been caused by hormonal abnormalities, however, it remains unclear whether this was due to the choriocarcinoma, SCTAT or both.

To date, only a small number of NGCO cases have been reported (Table I). Contralateral mature teratoma (18) or dysgerminoma (19) have been reported, whereby the bilateral tumors were of germ cell origin. Previously, endometrioid carcinoma, clear cell carcinoma and small cell carcinoma epithelial carcinoma with choriocarcinoma have also been reported, however, only a small proportion of these tumors exhibited a choriocarcinoma component (20). To the best of our knowledge, no cases of left NGCO with right ovarian SCTAT, as observed in case one, have been reported previously. The association between the two types of cancer remains unclear.

Large NGCOs often occur unilaterally, and exhibit extensive hemorrhage and necrosis (21). The disease is similar to gestational choriocarcinoma (22). Non-gestational choriocarcinomas are predominantly composed of two cell types:
Cytotrophoblasts, which are medium in size and rounded with lightly stained cytoplasm, clear cell boundaries and small, round, dark, central nuclei; and syncytiotrophoblasts, which exhibit cytoplasmic vacuoles, nuclei with coarse chromatin and unclear cellular boundaries, and occasionally form nodules. These two types of cells are typically arranged in cribriform, plexiform and pseudopapillary patterns within blood. Furthermore, NGCO tumors are commonly associated with dysgerminoma, teratoma, yolk sac tumors and other germ cell tumor components $(18,19)$, or may be a single component of choriocarcinoma; however, this is extremely rare. In the present study, no other germ cell tumors were identified in the two patients. The tumor cells of both cases were immunohistochemically positive for hCG and CK.

SCTAT with PJS often occur bilaterally, and are typically $<3 \mathrm{~cm}$ in diameter or only identified microscopically. In addition, calcifications are common in these tumors. By contrast, SCTAT without PJS are typically unilateral and larger in size. The tumor sections were solid or cystic and grayish-yellow in color. Microscopically, tumor cells surrounding the eosinophilic hyaline bodies formed simple or complex annular tubule epithelial nests. The tumor cell cytoplasms were lightly stained and the cellular boundaries were not clear. The nuclei were round and the hyaline bodies were in a palisade arrangement around the surrounding epithelial nests. Previously, IHC staining has revealed that the tumor cells express inhibin, CD99 and Melan-A (23). In case one, although the SCTAT of the right ovary was small with focal calcifications, no PJS or cervical lesions were present. Due to extensive tissue damage as a result of the choriocarcinoma, it was unclear whether a SCTAT component was present in the left ovary; thus, the association between SCTAT and PJS in the present case was difficult to determine.

Although NGCO primarily occurs in children, it may also occur in adults (24). Histologically, gestational choriocarcinoma and non-gestational choriocarcinoma share similar morphological features; therefore, for adolescents with no sexual history, the disease may be diagnosed according to the pathological features (25) and immunohistochemical phenotype. By contrast, for females of childbearing age, the difference between gestational and non-gestational choriocarcinoma is 
more difficult to confirm, however, DNA polymorphism analysis may aid diagnosis (14,26-29). Fisher et al (26) first used site-specific microsatellite probes to analyze DNA restriction fragment length polymorphisms of tumor tissue by comparing blood samples obtained from patients and their spouses. The results of were as follows: If the tumor components only originate from the patients, non-gestational choriocarcinoma may be diagnosed, whereas if a patrilineal component exists, gestational choriocarcinoma may be diagnosed.

NGCO must also be differentiated from embryonal carcinoma, dysgerminoma and intermediate trophoblastic tumors [placental site trophoblastic tumor (PSTT) and epithelioid trophoblastic tumor (ETT)]. Although embryonal carcinoma is composed of syncytiotrophoblast-like giant cells (30), it does not exhibit the bidirectional property of trophoblast cells in choriocarcinoma. Furthermore, upon IHC, embryonal carcinoma exhibits CD30 and AFP positivity, while choriocarcinoma exhibits CD30 and AFP negativity. A small number of dysgerminoma cases demonstrate syncytiotrophoblast differentiation without cytotrophoblasts, while tumor cell components are relatively simple, with positive PLAP and CD117, and negative hCG expression.

PSTTs do not contain cytotrophoblasts or syncytiotrophoblasts, however, the do exhibit pure intermediate trophoblastic cells. Furthermore, IHC analysis of choriocarcinoma shows diffuse positivity for hCG, while PSTTs exhibit only focal and weak positivity for hCG, and strong positivity for hPL. ETTs are composed of epithelioid trophoblasts without cytotrophoblasts and syncytiotrophoblasts, while only a small number of tumor cells exhibit focal hCG positivity $(31,32)$.

SCTAT must be differentiated from Sertoli cell tumors and microfollicular granulosa cell tumors. Microfollicular granulosa cell tumors containing Call-Exner bodies resemble SCTAT of the tubular lumen, however, such tumors are small with no visible nuclear debris or palisading nuclei. Highly differentiated Sertoli cell tumors may also form simple tubular structures with a hollow lumen (33).

NGCO often invades the adjacent organs and commonly metastasizes to distant organs (30), particularly the brain and lung. Treatment predominantly consists of surgery combined with chemotherapy, however, the efficacy of this strategy is not as high as that for gestational choriocarcinoma (34,35). Jiao et al (36) reported 21 cases of NGCO with a mean follow-up period of 71.4 months and an overall 5-year survival rate of $79.4 \%$. Goswami et al (18) summarized 30 case reports of NGCO and revealed that the 2 year survival rate of patients who accepted surgery combined with chemotherapy was $81 \%$, while that of patients who underwent surgery alone was $28 \%$. Although cases of SCTAT with PJS are clinically benign, recurrence and metastasis have been reported (37); $25 \%$ of SCTAT patients without PJS exhibit a malignant clinical course in which invasive growth of the tumor occurs (38). In the present study, the prognosis of case one was predominantly determined by the choriocarcinoma. Bilateral pulmonary metastases were identified following chemotherapy and the hCG level did not declined significantly. However, the treatment exhibited poor efficacy and the patient succumbed 3 months later. As indicated in Table I, pulmonary metastasis identified after surgery indicated the poor prognosis.
In conclusion, $\mathrm{NGCO}$ is a rare malignant germ cell tumor of which <100 cases have been reported worldwide $(21,36,38)$; therefore, limited clinical data is available. At present, no optimum treatment has been identified, and although the prognosis is worse than that of gestational choriocarcinoma, early detection, diagnosis and treatment are important factors for patient prognosis.

\section{References}

1. Heo EJ, Choi CH, Park JM, Lee JW, Bae DS and Kim BG: Primary ovarian choriocarcinoma mimicking ectopic pregnancy. Obstet Gynecol Sci 57: 330-333, 2014

2. Serno J, Zeppernick F, Jäkel J, Schrading S, Maass N, Meinhold-Heerlein I and Bauerschlag DO: Primary pulmonary choriocarcinoma: Case report and review of the literature. Gynecol Obstet Invest 74: 171- 176, 2012.

3. Rao KV, Konar S, Gangadharan J, Vikas V and Sampath S: A pure non-gestational ovarian choriocarcinoma with delayed solitary brain metastases: Case report and review of the literature. J Neurosci Rural Pract 6: 578-581, 2015.

4. Hu T, Yang M, Zhu H, Shi G and Wang H: Pure non-gestational ovarian choriocarcinoma in a $45, \mathrm{XO} / 46, \mathrm{XX}$ SRY-negative true hermaphrodite. J Obstet Gynaecol Res 37: 1900-1905, 2011.

5. Brown J, Sood AK, Deavers MT, Milojevic L and Gershenson DM: Patterns of metastasis in sex cord-stromal tumors of the ovary: Can routine staging lymphadenectomy be omitted? Gynecol Oncol 113: 86-90, 2009.

6. Scully RE: Sex cord tumor with annular tubules a distinctive ovarian tumor of the Peutz-Jeghers syndrome. Cancer 25: 1107-1121, 1970.

7. Young RH, Welch WR, Dickersin GR and Scully RE: Ovarian sex cord tumor with annular tubules: Review of 74 cases including 27 with Peutz-Jeghers syndrome and four with adenoma malignum of the cervix. Cancer 50: 1384-1402, 1982.

8. Han Y, Li S, Wu L, Zhang X and Cao D: Non-Peutz-Jeghers syndrome-associated ovarian sex cord tumor with annular tubules: Report of a malignant case. J Obstet Gynaecol Res 42: 224-227, 2016.

9. Kulkarni N: Recurrence of non-syndromic sex cord stromal tumor with annular tubules of ovary: Case report. Iran J Pathol 10: 61-64, 2015.

10. Choi YJ, Chun KY, Kim YW and Ro DY: Pure nongestational choriocarcinoma of the ovary: A case report. World J Surg Oncol 11: 7, 2013.

11. Waseda Y, Komai Y, Yano A, Fujii Y, Noguchi N and Kihara K: Pathological complete response and two-year disease-free survival in a primary gastric choriocarcinoma patient with advanced liver metastases treated with germ cell tumor-based chemotherapy: A case report. Jpn J Clin Oncol 42: 1197-1201, 2012.

12. Liu Y, Yang J, Ren T, Zhao J, Feng F, Wan X and Xiang Y: The encouraging prognosis of nongestational ovarian choriocarcinoma with lung metastases. J Reprod Med 59: 221-226, 2014.

13. Ramachandran BS, Murugesan M, Ali M and Padmanabhan P: Primary pancreatic choriocarcinoma presenting as pancreatitis. JOP 13: 217-218, 2012.

14. Hirata Y, Yanaihara N, Yanagida S, Fukui K, Iwadate K, Kiyokawa T and Tanaka T: Molecular genetic analysis of nongestational choriocarcinoma in a postmenopausal woman: A case report and literature review. Int J Gynecol Pathol 31: 364-368, 2012.

15. Jiao LZ, Xiang Y, Feng FZ, Wan XR, Zhao J, Cui QC and Yang XY: Clinical analysis of 21 cases of nongestational ovarian choriocarcinoma. Int J Gynecol Cancer 20: 299-302, 2010.

16. Park SH, Park A, Kim JY, Kwon JH and Koh SB: A case of non-gestational choriocarcinoma arising in the ovary of a postmenopausal woman. J Gynecol Oncol 20: 192-194, 2009.

17. Zaloudek CJ, States PN, Mooney EE and Young RH: Sex cord-stromal tumours - pure sex cord tumours. In: WHO classification of tumours of female reproductive organs. Kurman RJ, Carcangiu ML, Herrington CS and Young RH (eds). Vol 6. 4th edition. IARC Press, Lyon, pp53, 2014.

18. Goswami D, Sharma K, Zutshi V, Tempe A and Nigam S: Nongestational pure ovarian choriocarcinoma with contralateral teratoma. Gynecol Oncol 80: 262-266, 2001. 
19. Gungor T, Ekin M, Zergeroĝlu S and Gokmen O: Primary choriocarcinoma of the ovary with coexisting dysgerminoma of the contralateral ovary. J Obstet Gynaecol 19: 325-326, 1999.

20. Hirabayashi K, Yasuda M, Osamura RY, Hirasawa T and Murakami M: Ovarian nongestational choriocarcinoma mixed with various epithelial malignancies in association with endometriosis. Gynecol Oncol 102: 111-117, 2006.

21. Kong B, Tian YJ, Zhu WW and Qin YJ: A pure nongestational ovarian choriocarcinoma in a 10-year-old girl: Case report and literature review. J Obstet Gynaecol Res 35: 574-578, 2009.

22. Naniwadekar MR, Desai SR, Kshirsagar NS, Angarkar NN, Dombale VD and Jagtap SV: Pure choriocarcinoma of ovary diagnosed by fine needle aspiration cytology. Indian J Pathol Microbiol 52: 417-420, 2009.

23. Fan LD and Tang T: Application of immunohistochemistry in ovarian tumors and tumor-like lesions. Zhenduan Binglixue Zazhi 11: 369-372, 2004 (In Chinese).

24. Oladipo A, Mathew J, Oriolowo A, Lindsay I, Fisher R, Seckl M and Yiannakis D: Nongestational choriocarcinoma arising from a primary ovarian tumour. BJOG 114: 1298-1300, 2007.

25. Corakçi A, Ozeren S, Ozkan S, Gürbüz Y, Ustün H and Yücesoy I Pure nongestational choriocarcinoma of ovary. Arch Gynecol Obstet 271: 176-177, 2005.

26. Fisher RA, Newlands ES, Jeffreys AJ, Boxer GM, Begent RH, Rustin GJ and Bagshawe KD: Gestational and nongestational trophoblastic tumors distinguished by DNA analysis. Cancer 69 : 839-845, 1992.

27. Tsujioka H, Hamada H, Miyakawa T, Hachisuga $T$ and Kawarabayashi T: A pure nongestational choriocarcinoma of the ovary diagnosed with DNA polymorphism analysis. Gynecol Oncol 89: 540-542, 2003.

28. Koo HL, Choi J, Kim KR and Kim JH: Pure non-gestational choriocarcinoma of the ovary diagnosed by DNA polymorphism analysis. Pathol Int 56: 613-616, 2006.

29. Yamamoto E, Ino K, Yamamoto T, Sumigama S, Nawa A, Nomura S and Kikkawa F: A pure nongestational choriocarcinoma of the ovary diagnosed with short tandem repeat analysis: Case report and review of the literature. Int J Gynecol Cancer 17: 254-258, 2007.
30. Khuu HM, Crisco CP, Kilgore L, Rodgers WH and Conner MG: Carcinosarcoma of the uterus associated with a nongestational choriocarcinoma. South Med J 93: 226-228, 2000.

31. Zeng X, Liu X, Tian Q, Xue Y and An R: Placental site trophoblastic tumor: A case report and literature review. Intractable Rare Dis Res 4: 147-151, 2015.

32. Leow WQ, Loh HL, Lee LS and Goh CH: A rare case of combined placental site trophoblastic tumour with mature cystic teratoma and mixed germ cell tumour in the testis. Malays J Pathol 37: $145-147,2015$.

33. Duhig EE, Riha RL and Clarke BE: Test and teach. An unusual tumour presenting in the lungs. Metastatic adult granulosa cell tumour of the ovary, microfollicular patterns. Pathology 34: 78-81, 2002.

34. Gangadharan VP, Mathew BS, Kumar KS and Chitrathara K: Primary choriocarcinoma of the ovary. Report of two cases Indian J Cancer 36: 213-215, 1999.

35. Pentheroudakis G, White J, Davis J, Brown I and Vasey P: Concurrent ovarian-type primary peritoneal adenocarcinoma and peritoneal choriocarcinoma. A case report and review of the literature. Gynecol Oncol 92: 697-700, 2004.

36. Jiao LZ, Xiang Y, Feng FZ, Wan XR, Zhao J, Cui QC and Yang XY: Ovarian non-gestational choriocarcinoma clinical analysis of 21 cases. Chin J Prac Gynecol Obstet 25: 359-361, 2009 (In Chinese).

37. Barker D, Sharma R, McIndoe A, Blair E, Hall M, Gabra H and El-Bahrawy M: An unusual case of sex cord tumor with annular tubules with malignant transformation in a patient with Peutz-Jeghers syndrome. Int J Gynecol Pathol 29: 27-32, 2010.

38. Lv L, Yang K, Wu H, Lou J and Peng Z: Pure choriocarcinoma of the ovary: A case report. J Gynecol Oncol 22: 135-139, 2011. 